\title{
Chemical oxidation of ibuprofen in the presence of iron species at near neutral $\mathrm{pH}$
}

\author{
N. Sabri ${ }^{\text {a }}$ K. Hanna ${ }^{\text {b }}$, V. Yargeau ${ }^{\text {a, } *}$ \\ a Department of Chemical Engineering, McGill University, 3610 University Street, Montreal, Quebec, Canada H3A2B2 \\ b Ecole Nationale Supérieure de Chimie de Rennes, UMR CNRS 6226 “Sciences Chimiques de Rennes” Avenue du Général Leclerc, 35708 Rennes, France
}

\section{A R T I C L E I N F O}

\section{Article history:}

Received 7 February 2012

Received in revised form 9 April 2012

Accepted 10 April 2012

Available online 10 May 2012

\section{Keywords:}

Ibuprofen

Oxidation

Persulfate

Fenton reaction

Magnetite

\begin{abstract}
A B S T R A C T
The objective of this work was to evaluate the removal of ibuprofen (IBP) using the oxidants hydrogen peroxide $\left(\mathrm{H}_{2} \mathrm{O}_{2}\right)$ and sodium persulfate $\left(\mathrm{Na}_{2} \mathrm{~S}_{2} \mathrm{O}_{8}\right)$. The ability of magnetite $\left(\mathrm{Fe}_{3} \mathrm{O}_{4}\right)$ to activate persulfate (PS) and $\mathrm{H}_{2} \mathrm{O}_{2}$ for the oxidation of IBP at near neutral pH was evaluated as well. The use of soluble $\mathrm{Fe}^{2+}$ to activate $\mathrm{H}_{2} \mathrm{O}_{2}$ and $\mathrm{Na}_{2} \mathrm{~S}_{2} \mathrm{O}_{8}$ was also investigated. $\mathrm{H}_{2} \mathrm{O}_{2}$ and $\mathrm{Na}_{2} \mathrm{~S}_{2} \mathrm{O}_{8}$ were inactive during the sixty-minute experiments when used alone. However, activation using $\mathrm{Fe}^{2+}$ increased the removal to $95 \%$ in the presence of $\mathrm{H}_{2} \mathrm{O}_{2}$ (Fenton reaction) and $63 \%$ in the presence of $\mathrm{Na}_{2} \mathrm{~S}_{2} \mathrm{O}_{8}$ at $\mathrm{pH}$ 6.6. Chemical oxygen demand (COD) removal was also greater for Fenton oxidation (65\%) than for iron-activated PS oxidation (25\%). Activation of $\mathrm{H}_{2} \mathrm{O}_{2}$ and PS by $\mathrm{Fe}_{3} \mathrm{O}_{4}$ was only observed at a high oxidant concentration and over $48 \mathrm{~h}$ of reaction time. A second order rate kinetic constant was determined for $\mathrm{H}_{2} \mathrm{O}_{2}\left(3.0 * 10^{-3} \mathrm{M}^{-1} \mathrm{~s}^{-1}\right)$ and $\mathrm{Na}_{2} \mathrm{~S}_{2} \mathrm{O}_{8}$ $\left(1.59 * 10^{-3} \mathrm{M}^{-1} \mathrm{~s}^{-1}\right)$ in the presence of $\mathrm{Fe}_{3} \mathrm{O}_{4}$. Finally, several of the degradation products formed during oxidation of IBP in the presence of $\mathrm{H}_{2} \mathrm{O}_{2}$ and $\mathrm{Na}_{2} \mathrm{~S}_{2} \mathrm{O}_{8}$ (activated by $\mathrm{Fe}^{2+}$ ) were identified. These include oxalic acid, pyruvic acid, formic acid, acetic acid, 4-acetylbenzoic acid, 4-isobutylacetophenone (4-IBAP) and oxo-ibuprofen.
\end{abstract}

(c) 2012 Elsevier B.V. All rights reserved.

\section{Introduction}

Ibuprofen (2-(4-isobutylphenyl) propanoic acid) is a non steroidal anti inflammatory, antipyretic and analgesic drug. It is widely used for the treatment of inflammatory disorders such as rheumatoid arthritis and for pain relief. In 1984 it was approved as an over the counter drug and since then, non-prescription sales have tripled in North America (Caviglioli et al., 2002). IBP is degraded in the human body into its principal metabolites hydroxy-IBP, carboxy-IBP and to carboxy-hydratropic acid (Buser et al., 1999; Fent et al., 2006), which have been found together with IBP in raw sewage (Heberer, 2002). In Canada, IBP and one of its metabolites have been detected in the effluent of a primary wastewater treatment plant at concentrations greater than $500 \mathrm{ng} \mathrm{L}^{-1}$ (Gagnon and Lajeunesse, 2008) while in Europe and the US, concentrations of up to $10 \mu \mathrm{g} \mathrm{L} \mathrm{L}^{-1}$ were detected (Méndez-Arriaga et al., 2010; Pomati et al., 2004; Zorita et al., 2009). There is currently no quantified limit to the discharge of IBP in wastewater from manufacturing plants in Canada. However, considering that some physiological changes such as growth inhibition of a Macrophyte species (Lemna Minor) and stimulated production of the stress hormone abscisic acid in Lemna Minor (Pomati et al., 2004) have been linked to IBP, more stringent regulations are expected in the near future. Simple, efficient and cost-effective treatment options for the

\footnotetext{
* Corresponding author. Tel.: +1 514398 2273; fax: +1 5143986678. E-mail address: viviane.yargeau@mcgill.ca (V. Yargeau).
}

wash-water of vessels used in the production process of IBP-containing pills will thus become essential to the pharmaceutical industry. Various oxidation processes have been investigated for the removal of IBP in water but their efficiencies of removal have varied from no removal to complete removal (Caviglioli et al., 2002; Huber et al., 2003, 2005; Lee and von Gunten, 2009; Madhavan et al., 2010; Méndez-Arriaga et al., 2010, 2008; Skoumal et al., 2009). Furthermore, toxic transformation products were formed in a few cases (Caviglioli et al., 2002; Madhavan et al., 2010; Méndez-Arriaga et al., 2010). More work is thus still needed to identify the best treatment option(s) for IBP-containing industrial wastewaters.

All past research pertaining to the removal of IBP by the Fenton process only considered using soluble $\mathrm{Fe}^{2+}$ (traditional Fenton's reagent) and in most of these studies, low $\mathrm{pH}$ conditions $(\mathrm{pH}<4)$ were required to prevent the precipitation of iron (Méndez-Arriaga et al., 2010; Skoumal et al., 2009). Unlike the classical Fenton process, the reaction of Fe-bearing minerals with hydrogen peroxide $\left(\mathrm{H}_{2} \mathrm{O}_{2}\right)$ can effectively improve the oxidation of organic molecules at circumneutral $\mathrm{pH}$. This has been demonstrated for other contaminants such as 2,4,6-trinitrotoluene and phenol (Matta et al., 2007, 2008a, 2008b) but has yet to be shown for IBP. The degradation of pharmaceutical compounds by Fenton's reagent and a Fenton-like system has also been reported at acidic conditions (Goi et al., 2008; Hofmann et al., 2007; Méndez-Arriaga et al., 2010; Skoumal et al., 2009). However the removal of IBP at neutral pH, which is less abrasive to the environment, would be more appealing for applications in the treatment of wastewater or wash water that is produced in IBP processing plants. 
Persulfate (PS) was also proven to be very useful for the elimination of contaminants such as diphenylamine, trichloroethylene, benzene, toluene, ethyl benzene and xylene in aqueous and soil slurries (Liang et al., 2004a, 2004b, 2008). However, currently only one study investigated the use of PS or activated-PS for the elimination of a different pharmaceutical product, sulfamonomethoxine (Yan et al., 2010). Although the activation of PS by soluble iron to form a sulfate radical $\left(\mathrm{SO}_{4}{ }^{-}\right)$has been previously reported, the initiation of PS decomposition by iron oxide minerals has been scarcely investigated (Ahmad et al., 2010; Yan et al., 2010).

Minerals like ferrihydrite, goethite, manganese oxide and clay were used to activate the oxidation reaction of organic compounds (Ahmad et al., 2010). Fe ${ }^{\mathrm{II}}$-bearing minerals like magnetite $\left(\mathrm{Fe}_{3} \mathrm{O}_{4}\right)$ were found to be the most effective catalyst as compared to the only $\mathrm{Fe}^{\mathrm{III}}$ oxides for heterogeneous catalytic oxidation of organic pollutants (Ahmad et al., 2010; Matta et al., 2007, 2008b; Xue et al., 2009b, 2009c). In addition, $\mathrm{Fe}_{3} \mathrm{O}_{4}$ exhibited excellent structural and catalytic stabilities. $\mathrm{Fe}_{3} \mathrm{O}_{4}$ can be magnetically recovered and reused for several oxidation cycles; it is abundant in environmental settings and has a low solubility in aqueous solution (Schwertmann and Cornell, 2000; Xue et al., 2009a, 2009c). To date, the use of $\mathrm{Fe}_{3} \mathrm{O}_{4}$ (the most stable mixed valence oxide), to activate PS or $\mathrm{H}_{2} \mathrm{O}_{2}$, has not been tested for IBP removal.

The objectives of this study were to (i) examine the oxidation of IBP by $\mathrm{H}_{2} \mathrm{O}_{2}$ and $\mathrm{PS}$ at near neutral $\mathrm{pH}$, (ii) test the ability of soluble $\mathrm{Fe}^{\mathrm{II}}$ and $\mathrm{Fe}_{3} \mathrm{O}_{4}$ to activate $\mathrm{H}_{2} \mathrm{O}_{2}$ or PS, (iii) determine the extent of mineralization and identify the degradation products of IBP oxidation.

\section{Materials and methods}

\subsection{Chemicals}

Ibuprofen ( $\geq 98 \%$ ), magnetite powder $\left(\mathrm{Fe}_{3} \mathrm{O}_{4}, 98 \%\right)$, sodium persulfate $\left(\mathrm{Na}_{2} \mathrm{~S}_{2} \mathrm{O}_{8}, 99 \%\right)$, ammonium acetate $(\geq 99.9 \%)$ and iron chloride tetrahydrate $\left(\mathrm{FeCl}_{2} * 4 \mathrm{H}_{2} \mathrm{O}, \geq 99 \%\right)$ were purchased from SigmaAldrich. Hydrogen peroxide $\left(\mathrm{H}_{2} \mathrm{O}_{2} 35 \% \mathrm{w} / \mathrm{w}\right)$ was purchased from EMD Chemicals. HPLC grade methanol $(\geq 99.9 \%)$ and HPLC grade ammonium acetate $(\geq 99.0 \%)$ were purchased from Fisher Scientific. Hydrochloric acid $(\mathrm{HCl},>99 \%)$, sodium chloride $(\mathrm{NaCl},>99.5 \%)$, sodium hydroxide ( $\mathrm{NaOH}, 0.1 \mathrm{M})$, 4-acetylbenzoic acid (98\%), oxalic acid (>99\%), 4-ethylbenzaldehyde (98\%), formic acid (98\%), pyruvic acid (98\%) and acetic acid (98\%) were purchased from Sigma Aldrich. Oxo-ibuprofen was purchased from Santa Cruz Biotechnology Inc., and 4-isobutylacetophenone (4-IBAP, >96\%) from TCI America. Nitrogen $\left(\mathrm{N}_{2}, 99.99 \%\right)$ was purchased from Megs.

\subsection{Characterization of iron(II, III) oxide}

The X-Ray Diffraction (XRD) data were collected with a D8 Bruker diffractometer equipped with a monochromator and a positionsensitive detector to confirm the nature of the oxide $\left(\mathrm{Fe}_{3} \mathrm{O}_{4}\right)$ before and after the oxidative treatment. The X-ray source was a Co anode $(\lambda=0.17902 \mathrm{~nm})$. The diffractogram was recorded in the $3-64^{\circ} 2 \theta$ range, with a $0.0359^{\circ}$ step size and a collecting of $3 \mathrm{~s}$ per point. The particle size distribution of $\mathrm{Fe}_{3} \mathrm{O}_{4}$ was measured using a Mastersizer 2000 from Malvern Instruments. The Tristar 3000 from Quantachrome Instruments was used to determine the specific surface area of $\mathrm{Fe}_{3} \mathrm{O}_{4}$ by Nitrogen Brunauer-Emmett-Teller $\left(\mathrm{N}_{2}\right.$-BET) analysis. The point of zero charge (pzc) of $\mathrm{Fe}_{3} \mathrm{O}_{4}$ was determined through potentiometric titrations (Xue et al., 2009a).

Scanning Electron Microscopy (SEM) analysis was used to determine the morphology of the purchased $\mathrm{Fe}_{3} \mathrm{O}_{4}$. The SEM images were collected with a HITACHI FEG 54800 apparatus operated with a beam current of $3 \mathrm{pA}$ and an accelerating voltage of $20 \mathrm{kV}$ (analyzed microvolume of $\sim 6 \mu^{3}$ ). The solid powder was glued on an adhesive surface and metalized with a thin layer of gold.
Transmission Electron Microscopy (TEM) analysis was also performed to obtain information regarding the morphology, the size, shape and arrangement of the particles. TEM observations were carried out with a Philips CM20 TEM (200 kV) coupled with an EDAX energy dispersive X-ray spectrometer (EDXS). The solid powder was re-suspended in $2 \mathrm{~mL}$ ethanol under ultrasonication and a drop of suspension was evaporated on a carbon-coated copper grid which was placed on filter paper for analysis.

\subsection{Edge sorption and sorption isotherms}

Edge sorption experiments were conducted to determine the effect of $\mathrm{pH}$ on IBP sorption onto $\mathrm{Fe}_{3} \mathrm{O}_{4}$. A solution with final concentrations of $0.1 \mathrm{mM}$ IBP and $1 \mathrm{~g} \mathrm{~L}^{-1}$ of $\mathrm{Fe}_{3} \mathrm{O}_{4}$ ([Fe total] $=13 \mathrm{mM}$ ) was prepared in $10 \mathrm{mM} \mathrm{NaCl}$ ( $\mathrm{NaCl}$ was used as the supporting electrolyte). The $\mathrm{pH}$ was then adjusted using either $\mathrm{HCl}$ or $\mathrm{NaOH}$. For each $\mathrm{pH}$ value, $3 \mathrm{~mL}$ samples were extracted and filtered through $0.22 \mu \mathrm{m}$ polyvinylidene fluoride (PVDF) syringe filters (Millipore) that were previously shown not to sorb IBP. A UV-visible spectrophotometer (Agilent 8543 spectrophotometer) was used to determine the IBP concentration in solution at $273 \mathrm{~nm}$ and the adsorbed amount was calculated by the depletion method (Matta et al., 2007).

Sorption isotherms were determined at $20{ }^{\circ} \mathrm{C}$. Variable initial IBP concentrations $\left(0-0.5 \mathrm{mM}\right.$ ) were prepared with $\mathrm{Fe}_{3} \mathrm{O}_{4}$ (final concentration of $1 \mathrm{~g} \mathrm{~L}^{-1}$ ) at $\mathrm{pH} 6.6 \pm 0.2$. As before, the IBP solutions were prepared in $10 \mathrm{mM} \mathrm{NaCl}$. Before analysis, the suspensions were centrifuged, filtered and analyzed by UV-visible spectroscopy as previously described.

\subsection{Oxidation experiments}

$\mathrm{H}_{2} \mathrm{O}_{2}$ and $\mathrm{Na}_{2} \mathrm{~S}_{2} \mathrm{O}_{8}$ were used to degrade a $0.1 \mathrm{mM}$ solution of IBP (concentration in reverse osmosis water, representative of levels observed in industrial wastewater) in the presence and absence of both $\mathrm{Fe}^{2+}$ and $\mathrm{Fe}_{3} \mathrm{O}_{4}$. Experiments for optimization of oxidant concentration $\left(\mathrm{H}_{2} \mathrm{O}_{2}\right.$ and $\left.\mathrm{Na}_{2} \mathrm{~S}_{2} \mathrm{O}_{8}\right)$ were first conducted by varying the oxidant concentration between $1 \mathrm{mM}$ and $10 \mathrm{mM}$ in the presence and absence of $1 \mathrm{mM}$ of $\mathrm{Fe}^{2+}$. Replicates were then carried out under the optimal oxidant concentration (in the absence or presence of the iron species) in a $250 \mathrm{~mL}$ beaker sealed with parafilm and covered with aluminum foil to prevent any photo-transformation. The experiments were conducted at $\mathrm{pH}$ of $6.6 \pm 0.2 .3 \mathrm{~mL}$ samples were withdrawn at selected time intervals for $60 \mathrm{~min}$ and filtered using $0.22 \mu \mathrm{m}$ syringe filters and analyzed.

For the oxidation experiments using $\mathrm{Fe}_{3} \mathrm{O}_{4}, \mathrm{Fe}_{3} \mathrm{O}_{4}$ was added at a concentration of $1 \mathrm{~g} \mathrm{~L}^{-1}$ ([Fe total] $=13 \mathrm{mM}$ ) before the experiments were initiated. When $\mathrm{Fe}^{2+}$ was used, iron chloride tetrahydrate $\mathrm{FeCl}_{2}$ * $4 \mathrm{H}_{2} \mathrm{O}$ was added to the IBP solution to obtain a concentration of $1 \mathrm{mM}$ of $\mathrm{Fe}^{2+} . \mathrm{N}_{2}$ was bubbled in the solution to prevent the oxidation of $\mathrm{Fe}^{2+}$ to $\mathrm{Fe}^{3+}$ prior to commencing the experiment and throughout.

In order to determine the role of $\mathrm{Fe}_{3} \mathrm{O}_{4}$ in the kinetic investigation of IBP removal, oxidation experiments were also carried out using higher oxidant concentrations (10 mM) over a longer time frame (48 h).

\subsection{Analytical methods}

Residual IBP concentration were monitored using High Performance Liquid Chromatography (HPLC) (Agilent Technologies 1200 series) equipped with an Eclipse XDB C-18 ( $5 \mu \mathrm{m}, 4.6 \mathrm{~mm} \times 250 \mathrm{~mm}$ ) column (Agilent Technologies) using a diode array detector at a wavelength of $220 \mathrm{~nm}$ and $254 \mathrm{~nm}$. Mobile phases consisted of methanol and ammonium acetate $(20 \mathrm{mM}$ adjusted to $\mathrm{pH} 3.0$ using formic acid). The flow rate was $0.7 \mathrm{~mL} / \mathrm{min}$. The gradient used was the following; $0 \mathrm{~min}=60 \% \mathrm{~B}, 3 \% \mathrm{~A}, 2 \mathrm{~min}=67 \% \mathrm{~B}, 3 \% \mathrm{~A}, 4 \mathrm{~min}=74 \% \mathrm{~B}, 3 \% \mathrm{~A}$, $6 \mathrm{~min}=81 \% \mathrm{~B}, 3 \% \mathrm{~A}, 8 \mathrm{~min}=88 \% \mathrm{~B}, 3 \% \mathrm{~A}, 10 \mathrm{~min}=95 \% \mathrm{~B}, 3 \% \mathrm{~A}$, 
$12 \mathrm{~min}=97 \% \mathrm{~B}, 3 \% \mathrm{~A}$ and $25 \mathrm{~min}=97 \% \mathrm{~B}, 3 \% \mathrm{~A}$. Where $\mathrm{A}$ is ammonium acetate, $B$ is methanol and the remainder is reverse osmosis water.

The limit of detection of IBP of this method was $0.1 \mathrm{mg} \mathrm{L}^{-1}$ $(0.5 \mu \mathrm{M})$. The product identification was carried out by comparison with standards analyzed using a mass spectrometer (MDS/Sciex QTrap mass spectrometer) equipped with a Turbolon Spray ionization source operated in positive and negative ion mode.

The extent of mineralization was estimated using Chemical Oxygen Demand (COD) measured using a HACH Digital Reactor Block (DRB 200), a HACH spectrophotometer (DR/2500) and low range digestion vials $\left(0-150 \mathrm{mg} \mathrm{L}^{-1}\right)$. Ferrozine method was used to quantify the amount of $\mathrm{Fe}^{2+}$ (Kostka and N, 1998; Lovley and P, 1986). Total Fe was determined using Inductively Coupled Plasma Atomic Emission Spectroscopy (ICP-AES) (Thermo Trace Scan equipped with a minicrossflow nebulizer from SCP Science and a baffled quartz cyclonic spray chamber).

\section{Results and discussion}

\subsection{Characterization of $\mathrm{Fe}_{3} \mathrm{O}_{4}$}

The XRD diffractogram of $\mathrm{Fe}_{3} \mathrm{O}_{4}$ is shown in Fig. 1a. Five diffraction peaks at $2 \theta=21.2^{\circ}, 35^{\circ}, 41.2^{\circ}, 50.4^{\circ}$ and $62.8^{\circ}$ could be assigned to $\mathrm{Fe}_{3} \mathrm{O}_{4}$, (Schwertmann and Cornell, 2000). The d-space values of these main peaks were $2.53,2.96,2.09,4.85$ and $1.71 \AA$, which may respectively correspond to the more intense lines of $\mathrm{Fe}_{3} \mathrm{O}_{4} ; 311,220,400$, 111 and 422 . $\mathrm{Fe}_{3} \mathrm{O}_{4}$ is the only pure oxide of mixed valence and is usually represented by the formula $\left(\mathrm{Fe}^{3+}\right)_{\text {tet }}\left[\mathrm{Fe}^{3+} \mathrm{Fe}^{2+}\right]_{\text {oct }} \mathrm{O}_{4}$ (Xue et al., 2009a). It has a cubic spinel structure with iron in both tetrahedral and octahedral sites. The XRD diffractogram recorded at the end of oxidation reaction was found to be similar to that recorded before reaction, indicating good stability of $\mathrm{Fe}_{3} \mathrm{O}_{4}$ during the oxidation process. The surface area determined by BET method was $8.0 \mathrm{~m}^{2} \mathrm{~g}^{-1}$. The pzc value estimated from potentiometric titration was around 9.

SEM image shows that the $\mathrm{Fe}_{3} \mathrm{O}_{4}$ particles are highly aggregated and exhibit irregular shapes (Fig. 1b). The size of the particles is non-uniform and ranges between $\sim 100$ and $\sim 400 \mathrm{~nm}$. If we consider that the particles are spherical and have a density of $5.15 \times 10^{6} \mathrm{~g} \mathrm{~m}^{-3}$, the radius of these particles can be related to the surface area as $A=6 /(\rho \mathrm{d})=8 \mathrm{~m}^{2} \mathrm{~g}^{-1}$. Thus, the average diameter calculated assuming a spherical shape is $\sim 150 \mathrm{~nm}$.

TEM image (Fig. 1c) indicates that the $\mathrm{Fe}_{3} \mathrm{O}_{4}$ particles are more or less rhombohedral in shape, with crystals varying between 100 and $300 \mathrm{~nm}$ in length. TEM combined with EDXS yields an elemental analysis of the sample. Elemental ratios can be calculated by EDXS and compared with known mineralogical compositions. EDX microanalyses of samples before and after oxidation reactions showed the characteristic $\mathrm{Fe} / \mathrm{O}$ ratio of $\mathrm{Fe}_{3} \mathrm{O}_{4}$.

\subsection{Sorption of IBP onto $\mathrm{Fe}_{3} \mathrm{O}_{4}$}

The effect of varying the solution pH value (3-9) on the adsorption of IBP is illustrated in Fig. 2a. Sorption of IBP onto the iron oxide decreases sharply at $\mathrm{pH}$ values greater than 5 . The observed sorption behavior can be attributed to a combination of $\mathrm{pH}$-dependent speciation of IBP $\left(\mathrm{pK}_{\mathrm{a}}=4.54\right)$ and surface charge characteristics of the $\mathrm{Fe}_{3} \mathrm{O}_{4}$ $(\mathrm{pzc}=9)$. Based upon surface charging, adsorption is high at low $\mathrm{pH}$ values and then decreases when $\mathrm{pH}$ increases. The charge repulsion is expected at high $\mathrm{pH}$ where the sorbate and sorbent are both negatively charged. Such sorption behavior has also been observed for some

a

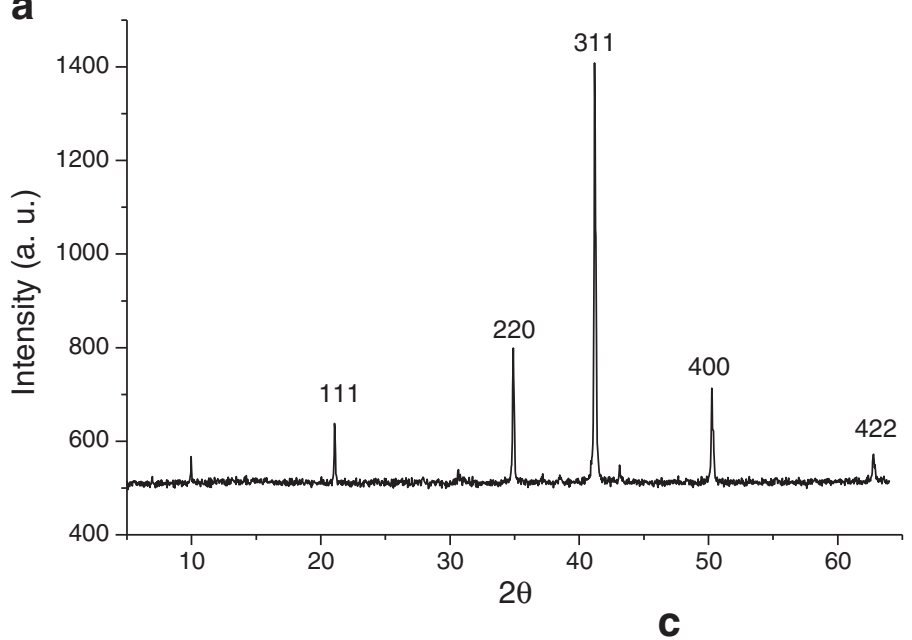

b
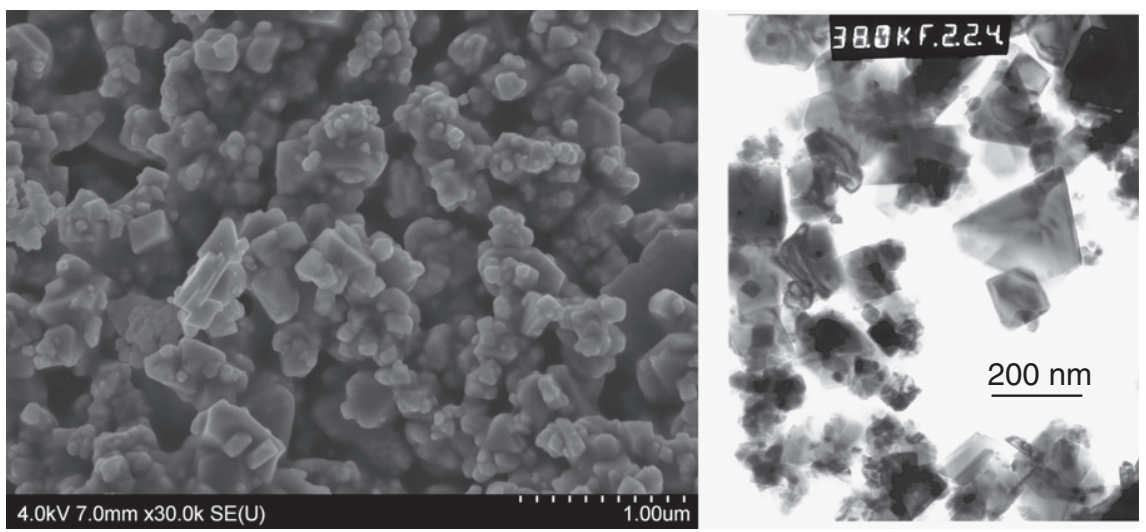

Fig. 1. (a) XRD diffractogramm (b) SEM and (c) TEM images of the $\mathrm{Fe}_{3} \mathrm{O}_{4}$ used. 

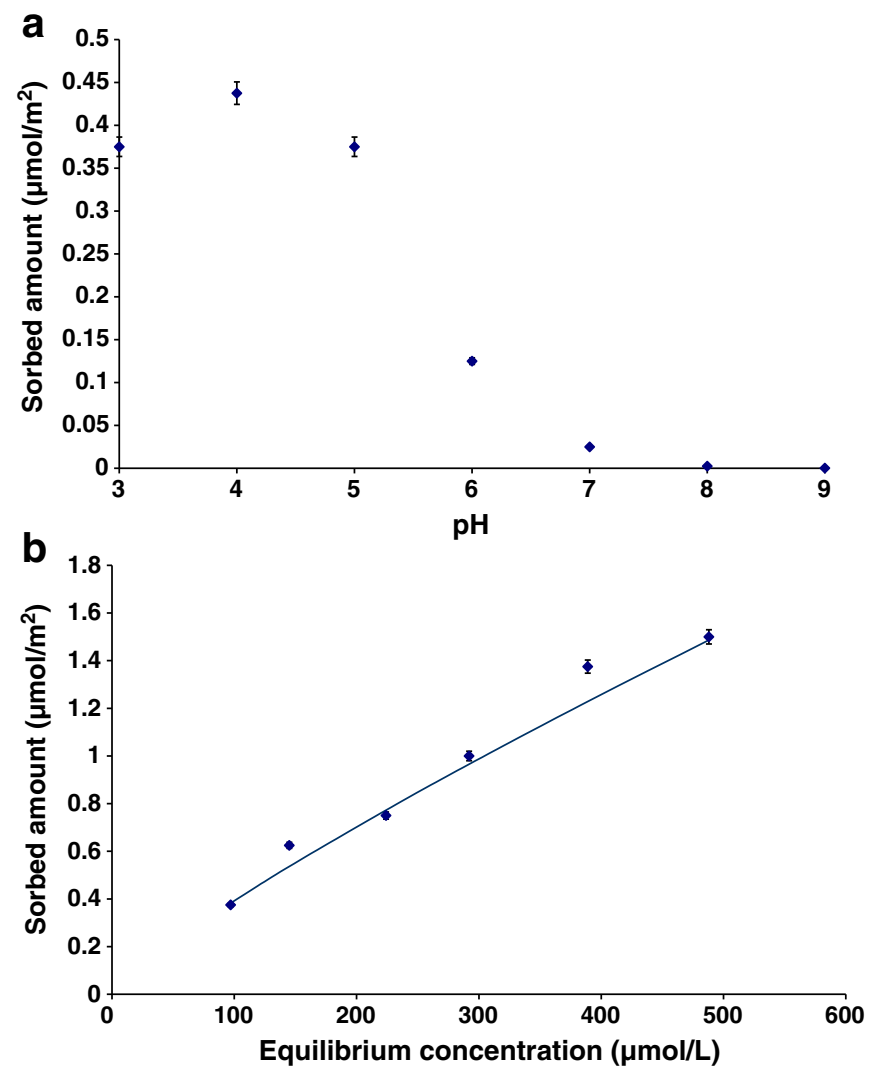

Fig. 2. (a) IBP sorption onto $\mathrm{Fe}_{3} \mathrm{O}_{4}$ vs $\mathrm{pH}$. $\left[\mathrm{Fe}_{3} \mathrm{O}_{4}\right]=1 \mathrm{~g} / \mathrm{L}$; $[\mathrm{IBP}]=0.1 \mathrm{mM} ; \mathrm{T}=20 \pm 1{ }^{\circ} \mathrm{C}$. (b) Sorption isotherms of IBP onto $\mathrm{Fe}_{3} \mathrm{O}_{4}$. $\left[\mathrm{Fe}_{3} \mathrm{O}_{4}\right]=1 \mathrm{~g} / \mathrm{L} ; \mathrm{T}=20 \pm 1{ }^{\circ} \mathrm{C}, \mathrm{pH} 6.6 \pm 0.1$; $\mathrm{t}=12 \mathrm{~h}$. The line represents the Freundlich model.

organic acid complexation on oxide surfaces (Evanko and Dzombak, 1999). In these studies, the adsorption envelope of monoprotic organic acids bound to iron oxide by surface complexation typically showed maximum adsorption at a $\mathrm{pH}$ near their corresponding $\mathrm{pK}_{\mathrm{a}}$.

Sorption isotherms were obtained to evaluate the effect of IBP concentration on sorption to $\mathrm{Fe}_{3} \mathrm{O}_{4}$ (Fig. 2b). The experimental isotherm data were fitted to the equations of Langmuir and Freundlich by applying linear regression analysis. One way to assess the goodness of fit of experimental isotherm data to these equations is to check the regression coefficients obtained during the regression analysis. On the basis of regression coefficient, the curves were shown a best fit with Freundlich isotherm at the studied range of solute concentration $(0-500 \mu \mathrm{mol} / \mathrm{L})$. The Freundlich equation has been used in the following form:

$Q=K_{F} C_{e}^{1 / n}$

where $\mathrm{Q}\left(\mu \mathrm{mol} / \mathrm{m}^{2}\right)$ is the sorbed concentration, $C_{e}(\mu \mathrm{mol} / \mathrm{L})$ is the equilibrium concentration at the end of the experiment and $\mathrm{K}_{\mathrm{F}}$ and $1 / \mathrm{n}$ are Freundlich constants. A plot $\left(R^{2}=0.98\right)$ of $\log Q$ versus $\log C_{e}$ enabled the determination of the Freundlich constants: $K_{F}=0.0082$ and $1 / \mathrm{n}=0.84$.

\subsection{Oxidation of IBP}

The first objective of the oxidation experiments was to optimize the concentration of $\mathrm{H}_{2} \mathrm{O}_{2}$ and $\mathrm{Na}_{2} \mathrm{~S}_{2} \mathrm{O}_{8}$ in presence of $1 \mathrm{mM}$ of $\mathrm{Fe}^{2+} . \mathrm{Fe}^{2+}$ concentration was chosen within the range reported in literature for Fenton and PS oxidation ( $\left[\mathrm{Fe}^{2+}\right]=0.5 \mathrm{mM}-5 \mathrm{mM}$ ) (Liang et al., 2004a; Méndez-Arriaga et al., 2010). The optimization of $\mathrm{H}_{2} \mathrm{O}_{2}$ concentration in the 1 to $10 \mathrm{mM}$ range at pH $6.6 \pm 0.2$ is illustrated in Fig. 3a. In the absence of iron species, an additional 15\% removal was observed when the concentration of $\mathrm{H}_{2} \mathrm{O}_{2}$ was increased by 10 fold (from $1 \mathrm{mM}$ to $10 \mathrm{mM}$ ). However, in the presence of $\mathrm{Fe}^{2+}$, increasing $\mathrm{H}_{2} \mathrm{O}_{2}$ concentration had no effect on the removal of IBP. Therefore, the value of $1 \mathrm{mM}$ was chosen for the rest of the experiments.

Optimization experiments for PS oxidation were conducted by varying $\mathrm{Na}_{2} \mathrm{~S}_{2} \mathrm{O}_{8}$ concentrations $(0.5 \mathrm{mM}-2.57 \mathrm{mM})$ alone and in the presence of a fixed $\mathrm{Fe}^{2+}$ concentration (Fig. $3 \mathrm{~b}$ ). $\mathrm{Fe}^{2+}$ was set at $1 \mathrm{mM}$ in accordance with literature and more importantly, in order to allow comparison to the Fenton experiments. As illustrated in Fig. 3b, at pH $6.6 \pm 0.2$ no difference in removal was observed between $1 \mathrm{mM}$ and $2.57 \mathrm{mM}$ of PS. $\mathrm{Fe}^{2+}$ content was measured at the end of the experiment using the Ferrozine method. None was detected after $60 \mathrm{~min}$ of treatment, indicating that all $\mathrm{Fe}^{2+}$ had been completely reacted. Therefore, $1 \mathrm{mM}$ of $\mathrm{Na}_{2} \mathrm{~S}_{2} \mathrm{O}_{8}$ or $\mathrm{H}_{2} \mathrm{O}_{2}$ was selected as optimal concentration for all oxidation experiments.

As shown in Fig. 4a, $1 \mathrm{mM}$ of $\mathrm{H}_{2} \mathrm{O}_{2}$ used alone or in the presence of $\mathrm{Fe}_{3} \mathrm{O}_{4}$ led to minimal removal $(<1 \%)$ over $60 \mathrm{~min}$ of reaction time. The oxidation ability of $\mathrm{H}_{2} \mathrm{O}_{2}$ was strongly enhanced by adding a small quantity of readily available $\mathrm{Fe}^{2+}$ which produces $\mathrm{Fe}^{3+}$, hydroxyl radicals $(\mathrm{OH} \bullet)$ and hydroxide anions $\left(\mathrm{OH}^{-}\right)$as demonstrated in previous studies (Méndez-Arriaga et al., 2010; Poyatos et al., 2009; Weiss, 1952). A removal of $95 \%$ was obtained after a reaction time of $60 \mathrm{~min}$ under these conditions.

Méndez-Arriaga et al. (2010) reported that IBP $\left(C_{o}=0.87 \mathrm{mM}\right)$ subjected to varying concentrations of $\mathrm{H}_{2} \mathrm{O}_{2}\left(8.7 \times 10^{-4} \mathrm{mM}-8.7 \mathrm{mM}\right)$ at a $\mathrm{pH}$ and temperature similar to the research presented here resulted in
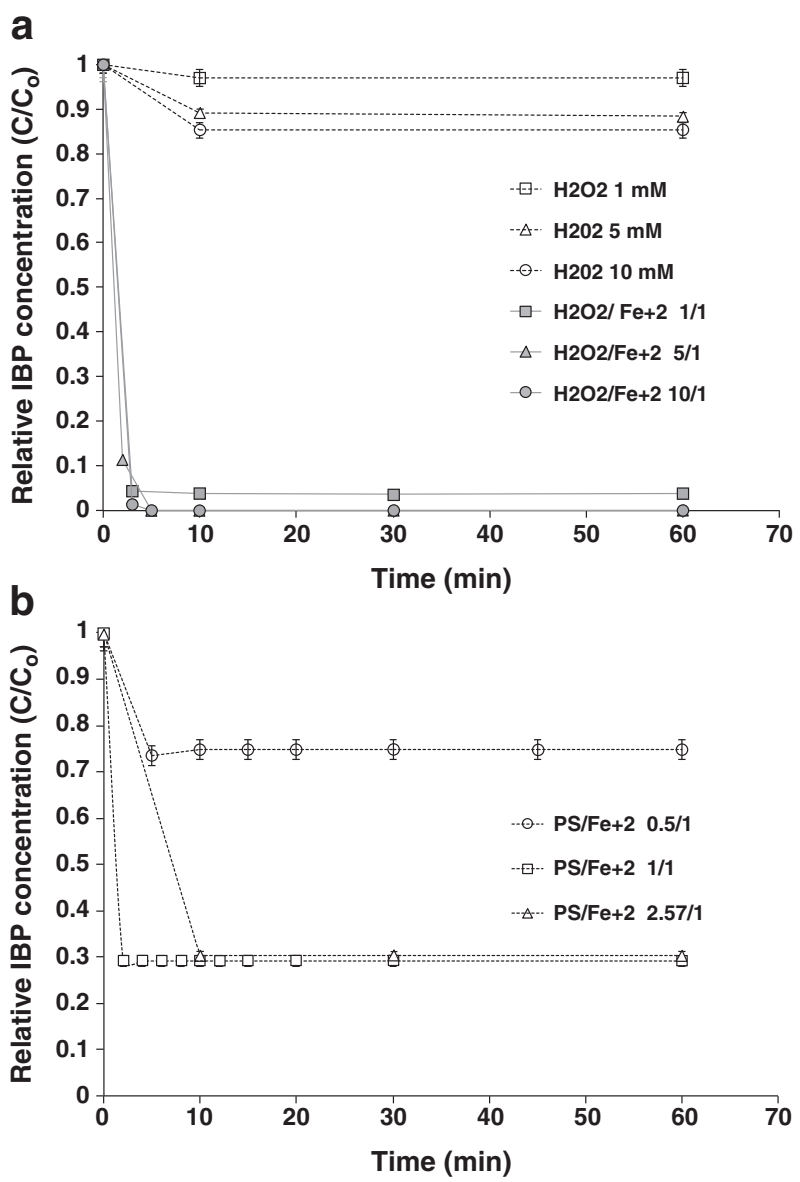

Fig. 3. (a) Removal profile of IBP at various $\mathrm{H}_{2} \mathrm{O}_{2}$ concentrations $\left[\mathrm{H}_{2} \mathrm{O}_{2}\right]$ : ( $\square$ ) $1 \mathrm{mM},(\Delta)$ $5 \mathrm{mM}$ and (o) $10 \mathrm{mM}$; and in presence of fixed $\mathrm{Fe}^{2+}$ concentration $\left[\mathrm{Fe}^{2+}\right]=1 \mathrm{mM},\left[\mathrm{H}_{2} \mathrm{O}_{2}\right]$ : (অ) $1 \mathrm{mM},(\boldsymbol{\Delta}) 5 \mathrm{mM}$ and (ט) $10 \mathrm{mM}$. (b) Removal profile of IBP at various PS concentrations in the presence of fixed $\mathrm{Fe}^{2+}$ concentration $\left[\mathrm{Fe}^{2+}\right]=1 \mathrm{mM}$, [PS]: (o) $0.5 \mathrm{mM}(\square)$ $1 \mathrm{mM}$ and $(\Delta) 2.57 \mathrm{mM}$. [IBP] $=0.1 \mathrm{mM} ; \mathrm{T}=20 \pm 1{ }^{\circ} \mathrm{C}$. 


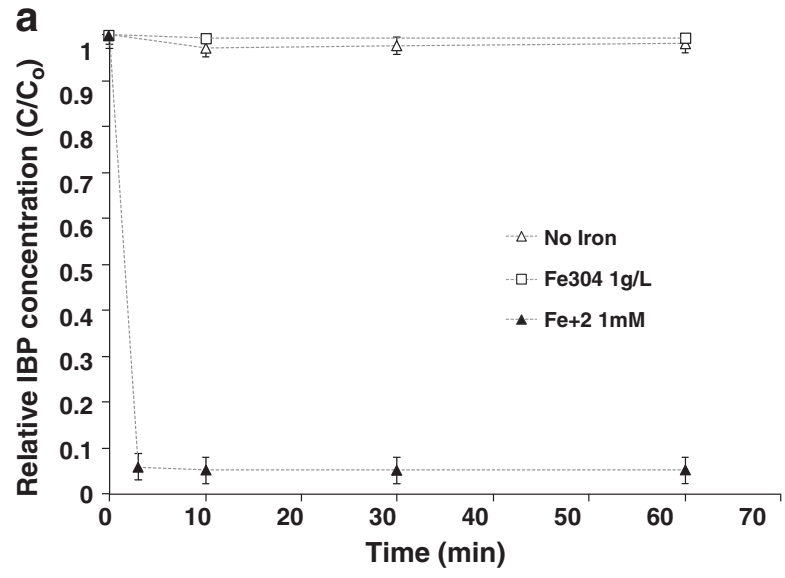

b

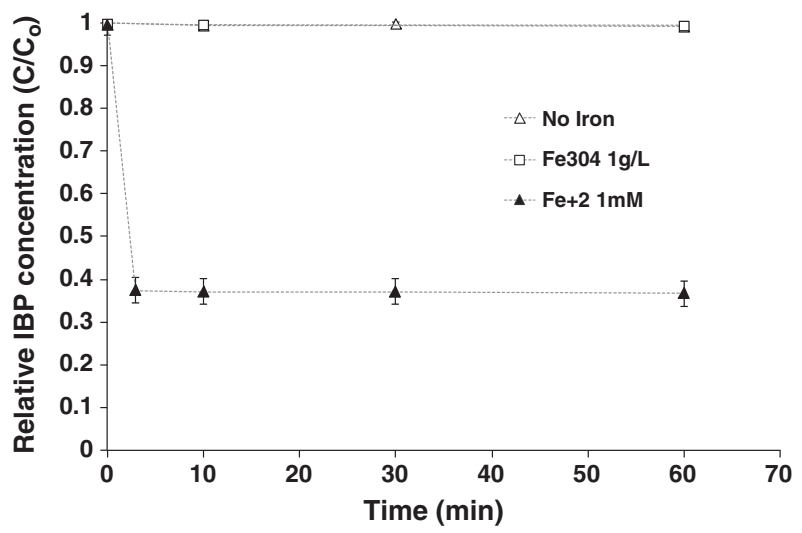

Fig. 4. (a) Oxidation of IBP by $\mathrm{H}_{2} \mathrm{O}_{2}$ or (b) $\mathrm{Na}_{2} \mathrm{~S}_{2} \mathrm{O}_{8}$ in the presence and absence of iron species; $(\Delta)$ absence of iron, $(\square)\left[\mathrm{Fe}_{3} \mathrm{O}_{4}\right]=1 \mathrm{~g} \mathrm{~L}^{-1},(\boldsymbol{\Delta})\left[\mathrm{Fe}^{2+}\right]=1 \mathrm{mM}$. [ [BP] $=$ $0.1 \mathrm{mM}$; [oxidant $=1 \mathrm{mM} ; \mathrm{T}=20 \pm 1{ }^{\circ} \mathrm{C}$.

no removal after $2 \mathrm{~h}$ of treatment time. However, they showed that increasing $\mathrm{Fe}^{2+}$ concentrations (0.15-1.2 mM) led to higher IBP degradation with an initial $\mathrm{H}_{2} \mathrm{O}_{2}$ concentration fixed at $0.32 \mathrm{mM}$. The maximum removal achieved was $60 \%$ under the following conditions: $\mathrm{IBP}=0.87 \mathrm{mM}, \mathrm{Fe}^{2+}=1.2 \mathrm{mM}$ and $\mathrm{H}_{2} \mathrm{O}_{2}=0.32 \mathrm{mM}$. This is significantly less than the 95\% removal observed in the work presented herein. This could be attributed to two factors: 1 ) the lower ratio of $\mathrm{H}_{2} \mathrm{O}_{2}$ : $\mathrm{Fe}^{2+}(1: 4)$ which would lead to a reduced generation of $\mathrm{OH} \bullet$ and 2) the higher initial concentration of IBP ( 9 times greater than the IBP concentration used in this work) leading to reduced number of oxidizing species per mole of IBP.

During PS oxidation, negligible removal was observed in the absence of iron species and in the presence of $\mathrm{Fe}_{3} \mathrm{O}_{4}$ while a $63 \%$ removal was obtained in presence of $\mathrm{Fe}^{2+}$ after 60 min (Fig. 4b). The highly significant impact of adding $\mathrm{Fe}^{2+}$ can be explained as follows. The PS anion $\left(\mathrm{S}_{2} \mathrm{O}_{8}^{2-}\right)$ has a high redox potential $\left(\mathrm{E}^{\mathrm{o}}=2.01 \mathrm{~V}\right)$ and is chemically activated by $\mathrm{Fe}^{2+}$ to form the sulfate radical $\left(\mathrm{SO}_{4^{\circ}}{ }^{-}\right.$), which is an even stronger oxidant $\left(\mathrm{E}^{\mathrm{O}}=2.4\right)$ (Liang et al., 2004a). $\mathrm{SO}_{4^{\circ}}{ }^{-}$can also react with water or $\mathrm{OH}^{-}$to generate $\mathrm{OH} \bullet$ (Peyton, 1993). Furthermore, $\mathrm{OH} \bullet$ can initiate a series of propagation reactions that generate perhydroxyl radicals, superoxide radical anions and hydroperoxide anions (Monahan et al., 2005). However, $\mathrm{Fe}_{3} \mathrm{O}_{4}$ cannot activate PS to form $\mathrm{SO}_{4}{ }^{\cdot-}$ under our experimental conditions (Fig. 4b). Yan et al. (2010) reported that $\mathrm{Fe}_{3} \mathrm{O}_{4}$ used at a high concentration hindered the PS oxidation of sulfamonomethoxine. In the present work, the high concentration of $\mathrm{Fe}_{3} \mathrm{O}_{4}$ may have scavenged the $\mathrm{SO}_{4}{ }^{\bullet}$, leading to the transformation of the radical into the sulfate anion $\left(\mathrm{SO}_{4}^{2-}\right)$. This scavenging effect was also observed in previous studies for the heterogeneous Fenton reaction at a high loading of $\mathrm{Fe}_{3} \mathrm{O}_{4}$ (Xue et al., 2009a, 2009b).
An important observation made during these experiments was that $\mathrm{Fe}^{2+}$ quickly oxidized for an almost instantaneous oxidation of IBP; then, the reaction was stalled. This behavior was also observed in the studies of Liang et al. (2004a and 2008) for the PS oxidation of trichloroethylene (TCE) and benzene-toluene-ethylbenzene-xylene (BTEX) compounds. It was hypothesized that this behavior was due to either the destruction of $\mathrm{SO}_{4}{ }^{-}$in the presence of excess $\mathrm{Fe}^{2+}$ or the rapid conversion of $\mathrm{Fe}^{2+}$ to $\mathrm{Fe}^{3+}$ (Liang et al., 2004a, 2008). The instantaneous change in color observed when PS was added and the formation of an iron hydroxide precipitate $\left(\mathrm{Fe}(\mathrm{OH})_{3}\right)$ within the first 3 min strongly suggests that the oxidation of $\mathrm{Fe}^{2+}$ was very rapid. In addition, combination of $\mathrm{SO}_{4}{ }^{-}-$may occur due to an excess of radicals being formed.

Note that kinetic rate constants cannot be determined for the above mentioned oxidation experiments because the removal of IBP in the absence of iron species or presence of $\mathrm{Fe}_{3} \mathrm{O}_{4}$ was insignificant over the studied reaction time. Furthermore, kinetic investigation was also not considered in the presence of $\mathrm{Fe}^{2+}$ due to the rapidity of the reaction, making it impossible to sample over the short reaction time. The following section discusses the kinetic removal of IBP under an extended time frame ( $48 \mathrm{~h}$ ) and using a higher initial oxidant concentration in the presence of $\mathrm{Fe}_{3} \mathrm{O}_{4}$.

\subsection{Kinetic of IBP removal using $\mathrm{Fe}_{3} \mathrm{O}_{4}$}

In order to determine the role of $\mathrm{Fe}_{3} \mathrm{O}_{4}$ on the kinetics of IBP removal, oxidation experiments were carried out using a higher oxidant concentration $(10 \mathrm{mM})$ over a longer time frame $(48 \mathrm{~h})$ as proposed in a previous work (Xue et al., 2009a). As illustrated in Fig. 5, the removal of IBP by $\mathrm{H}_{2} \mathrm{O}_{2}$ alone is minimal ( 20\%) which is in agreement with previous studies (Méndez-Arriaga et al., 2010; Skoumal et al., 2009). Conversely, $\mathrm{H}_{2} \mathrm{O}_{2}$ oxidation is significantly enhanced by the presence of $\mathrm{Fe}_{3} \mathrm{O}_{4}(\sim 60 \%)$. This behavior was also observed for IBP removal by PS, where the removal was increased from $58 \%$ to $73 \%$. The increase in removal for both oxidants is due to the adsorption of IBP onto $\mathrm{Fe}_{3} \mathrm{O}_{4}$ and to the increased formation of either $\mathrm{SO}_{4}{ }^{-}$or $\mathrm{OH} \cdot$. This is a result of using larger initial oxidant concentrations which target the IBP molecule due to the radical's non-selective behavior.

To determine rate constants for $\mathrm{Fe}_{3} \mathrm{O}_{4}$-activated $\mathrm{H}_{2} \mathrm{O}_{2}$ and $\mathrm{Na}_{2} \mathrm{~S}_{2} \mathrm{O}_{8}$, the raw data was fit to a second order reaction;

$k * t=\frac{1}{C_{a}}-\frac{1}{C_{a o}}$

where $\mathrm{k}$ is the rate order constant $\left(\mathrm{M}^{-1} \mathrm{~s}^{-1}\right), \mathrm{t}$ is the time $(\mathrm{s}), \mathrm{C}_{\mathrm{ao}}$ is the initial concentration of IBP and $\mathrm{C}_{\mathrm{a}}(\mathrm{mM})$ is the remaining concentration of IBP (mM).

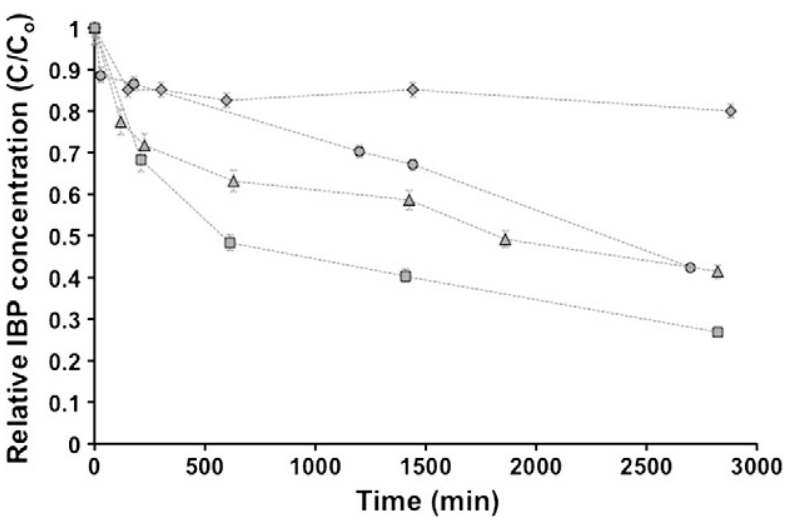

Fig. 5. Oxidation of IBP in the presence of $(\bullet)\left[\mathrm{H}_{2} \mathrm{O}_{2}\right]=10 \mathrm{mM},(\bullet)\left[\mathrm{Na}_{2} \mathrm{~S}_{2} \mathrm{O}_{8}\right]=10 \mathrm{mM}$, (४) $\left[\mathrm{H}_{2} \mathrm{O}_{2}\right]=10 \mathrm{mM}+\left[\mathrm{Fe}_{3} \mathrm{O}_{4}\right]=1 \mathrm{~g} \mathrm{~L}^{-1}$ and (U) $\left[\mathrm{Na}_{2} \mathrm{~S}_{2} \mathrm{O}_{8}\right]=10 \mathrm{mM}+\left[\mathrm{Fe}_{3} \mathrm{O}_{4}\right]=1 \mathrm{~g} \mathrm{~L}^{-1}$ $[\mathrm{IBP}]=0.1 \mathrm{mM} ; \mathrm{T}=20 \pm 1{ }^{\circ} \mathrm{C}$. 
The rate constants for the removal of IBP by the oxidizing species formed were determined to be: $1.59 * 10^{-3} \mathrm{M}^{-1} \mathrm{~s}^{-1}$ for PS and $3.0 * 10^{-3} \mathrm{M}^{-1} \mathrm{~s}^{-1}$ for $\mathrm{H}_{2} \mathrm{O}_{2}$ in the presence of $\mathrm{Fe}_{3} \mathrm{O}_{4}$. When comparing these results to those obtained by Huber et al. (2003) and Lee and von Gunten (2009), the second order rate constant for the reaction of $\mathrm{OH} \bullet$ with $\operatorname{IBP}\left(7.4 \times 10^{9} \mathrm{M}^{-1} \mathrm{~s}^{-1}\right)$ is approximately 12 orders of magnitude greater than to $\mathrm{Na}_{2} \mathrm{~S}_{2} \mathrm{O}_{8}$ and $\mathrm{H}_{2} \mathrm{O}_{2}$ in presence of $\mathrm{Fe}_{3} \mathrm{O}_{4}$. No study has presented the reaction rate constant for IBP removal by $\mathrm{SO}_{4}{ }^{-}$. In the case of PS and Fenton oxidation, we have seen that $\mathrm{Fe}_{3} \mathrm{O}_{4}$ can indeed promote the formation of $\mathrm{SO}_{4}{ }^{-}$and $\mathrm{OH} \cdot$, however this is hindered if the catalyst loading is too large as these conditions lead to a scavenging effect. Lee and von Gunten (2009) demonstrated that selective oxidants only react with some electron-rich organic moieties, (such as phenols, anilines, olefins, and deprotonatedamine) which are not present in IBP. Therefore the low reaction rate constants can be justified by the scavenging effect of the radicals formed and the non-selective behavior of the oxidants.

\subsection{COD abatement vs. time and identification of degradation products}

In order to determine the extent of mineralization, COD was determined in the absence of iron species and in the presence of $\mathrm{Fe}^{2+}$ for both oxidants $\left(\mathrm{H}_{2} \mathrm{O}_{2}\right.$ or $\left.\mathrm{Na}_{2} \mathrm{~S}_{2} \mathrm{O}_{8}\right)$. Fig. 6 presents the average removal obtained with the error bars representing the minimum and maximum values of the replicates. No COD removal was observed for $\mathrm{H}_{2} \mathrm{O}_{2}$ and $\mathrm{PS}$ alone. The addition of $\mathrm{Fe}^{2+}$ enhanced the COD removal to $65 \%$ and $25 \%$ for $\mathrm{H}_{2} \mathrm{O}_{2}$ and $\mathrm{PS}$, respectively.

Different products were detected as new peaks on the HPLC chromatogram of the samples collected during oxidation with $\mathrm{Fe}^{2+}$. Four of the most abundant degradation products, detected at retention times of 4.6, 4.8, 8.8 and $10.1 \mathrm{~min}$, were collected as fractions. These fractions were analyzed by mass spectrometry (MS) by comparison with standards of compounds reported in literature as potential degradation products of IBP. Table 1 presents these products which were confirmed to be: 4-acetylbenzoic acid, oxalic acid, oxo-ibuprofen and 4-isobutylacetophenone (4-IBAP). 4-IBAP has previously been detected in the environment at the inlet and outlet of a tertiary sewage treatment plant in Sweden (Zorita et al., 2009). Furthermore this product has proven to be quite toxic and the subsequent effects of the compound on the central nervous system are well known (Miranda et al., 1991). No information regarding the persistence or toxicity of 4acetylbenzoic acid and oxo-ibuprofen has been presented in literature.

Further MS analysis also confirmed the presence of formic acid, pyruvic acid and acetic acid in the treated solution but the presence of 4-ethylbenzaldehyde, also proposed in literature as a potential product, was not confirmed. However, 4-ethylbenzaldehyde is known to have a sweet smell and during the oxidation experiments this type of

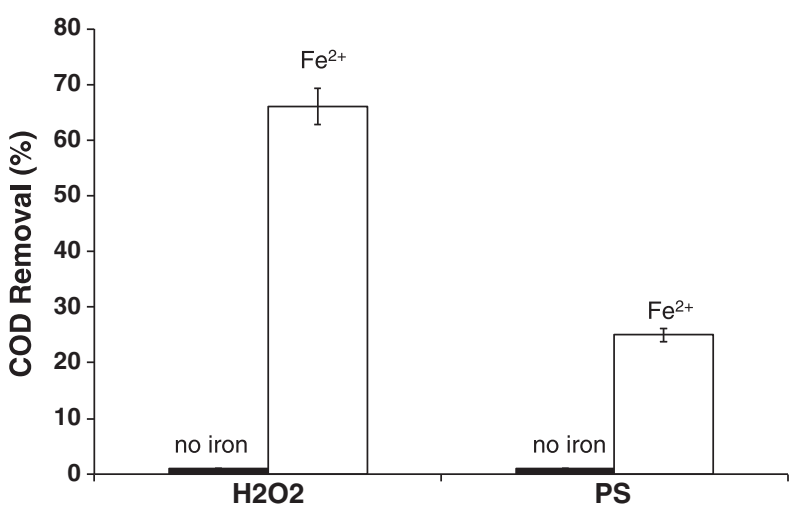

Fig. 6. COD removal of IBP in the absence of iron species and presence of $\mathrm{Fe}^{2+}$.
Table 1

Degradation products detected by LC and confirmed by MS

Product

odor was frequently detected and may suggest that this volatile product was formed but did not accumulate in the treated solution. One study determined the lethal dose $\left(\mathrm{LD}_{50}\right)$ on rats to be $1970 \mathrm{mg} \mathrm{kg}^{-1}$ of body weight (Adams et al., 2005). The value presented in literature is not of concern because it is several orders of magnitude higher than what is produced during oxidation. Acetic acid is thought to be formed from pyruvic acid degradation, which has been determined to be a by-product of 4-IBAP. Oxalic acid is mainly formed from the oxidative breakdown of the aryl moiety of aromatics and is largely formed from oxidation of pyruvic and acetic acid. Furthermore, similarly to

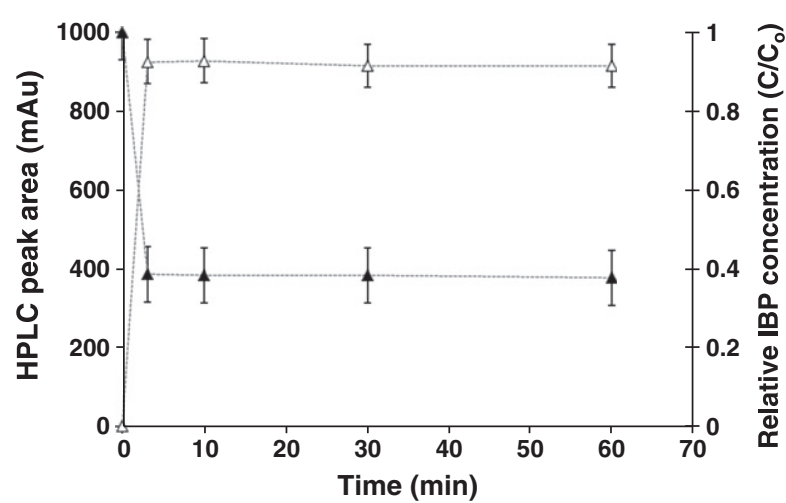

Fig. 7. Right axis: removal of IBP with PS activated by $\mathrm{Fe}^{2+}(\boldsymbol{\Delta})$. Left axis: degradation product formed at retention time 13.2 min during removal of IBP with PS activated by $\mathrm{Fe}^{2+}(\Delta) .[\mathrm{IBP}]=0.1 \mathrm{mM} ;=1 \mathrm{mM} ; \mathrm{T}=20 \pm 1{ }^{\circ} \mathrm{C} ; \mathrm{t}=1 \mathrm{~h}$. 
oxalic acid, formic acid is an ultimate carboxylic acid since it is directly transformed into $\mathrm{CO}_{2}$ (Adams et al., 2005; Skoumal et al., 2009).

Due to the low concentration of the degradation products relative to the limit of detection of the HPLC method used, it was not possible to investigate the persistence of the degradation products formed. The peak area of only one degradation product, detected at a retention time of $13.2 \mathrm{~min}$, could be monitored with respect to time. As shown in Fig. 7, this degradation product, which could not be identified by LC-MS, was continuously removed over a period of $30 \mathrm{~min}$ even though IBP oxidation had terminated after 3 min during $\mathrm{Fe}^{2+}$ activated PS oxidation. This suggests that there are still oxidizing species present in solution, such as $\mathrm{S}_{2} \mathrm{O}_{8}^{2-}$ which inevitably contributes to the removal of the degradation products.

In the work of Caviglioli et al. (2002), it was noted that several degradation products of IBP form during thermal and oxidative treatments (treatments include; $\mathrm{KMnO}_{4}, \mathrm{H}_{2} \mathrm{O}_{2}$ and $\mathrm{K}_{2} \mathrm{Cr}_{2} \mathrm{O}_{7}$ ). Only three degradation products detected here were the same as those found in Caviglioli et al. (2002), which were 4-acetylbenzoic acid, oxoibuprofen and 4-IBAP. Méndez-Arriaga et al. (2010) reported that hydroxylated byproducts were formed during Fenton treatment and that decarboxylated and hydroxylated byproducts were formed during photo-Fenton treatment (Méndez-Arriaga et al., 2010). Based on the products identified in our study, especially formic acid, which can be formed from decarboxylation of IBP, decarboxylation was thought to be the main mechanism of degradation.

\section{Conclusion}

The aim of this work was to test the ability of soluble $\mathrm{Fe}^{2+}$ and $\mathrm{Fe}_{3} \mathrm{O}_{4}$ to activate both $\mathrm{H}_{2} \mathrm{O}_{2}$ and PS. $\mathrm{H}_{2} \mathrm{O}_{2}$ and $\mathrm{Na}_{2} \mathrm{~S}_{2} \mathrm{O}_{8}$ without activation had little effect on IBP removal. When $\mathrm{Fe}^{2+}$ was introduced into the system, the removal was greatly enhanced. The removal efficiency increased to $95 \%$ in the presence of $\mathrm{H}_{2} \mathrm{O}_{2}$ and to $63 \%$ in the presence of $\mathrm{Na}_{2} \mathrm{~S}_{2} \mathrm{O}_{8}$ at $\mathrm{pH}$ 6.6. This behavior was also reflected in the COD results.

The $\mathrm{Fe}_{3} \mathrm{O}_{4} / \mathrm{H}_{2} \mathrm{O}_{2}$ system was also shown for the first time to effectively degrade IBP through a heterogeneous Fenton reaction. The presence of $\mathrm{Fe}_{3} \mathrm{O}_{4}$ activated PS oxidation of IBP through the possible formation of reactive species such as $\mathrm{SO}_{4}{ }^{-}$and $\mathrm{OH} \bullet$. A higher kinetic rate constant was found for the oxidation of IBP by $\mathrm{H}_{2} \mathrm{O}_{2}$ compared to PS in the presence of magnetite. This is the first study to present the reaction rate constant for IBP removal by the $\mathrm{SO}_{4}{ }^{-}$. Although the kinetics of Fenton-like and PS reactions are slower than those of homogeneous oxidation reactions using $\mathrm{Fe}^{2+}$, the use of $\mathrm{Fe}_{3} \mathrm{O}_{4}$ as an iron source offers many advantages for engineering application purposes. First, $\mathrm{Fe}_{3} \mathrm{O}_{4}$ can be used under a wide $\mathrm{pH}$ range, unlike homogeneous $\mathrm{Fe}^{2+}$ which has a risk of precipitating out at high $\mathrm{pH}$ values. Secondly, due to its magnetic properties, $\mathrm{Fe}_{3} \mathrm{O}_{4}$ particles may be easily separated or recovered from aqueous solutions unlike $\mathrm{Fe}^{2+}$ which can form iron sludges. In addition, $\mathrm{Fe}_{3} \mathrm{O}_{4}$ was shown to be re-usable for further oxidation cycles without attrition and has a low loss of iron content. Furthermore, $\mathrm{Fe}_{3} \mathrm{O}_{4}$ has a good structural stability during oxidation cycles at neutral pH (Xue et al., 2009a). Therefore it can be hypothesized that re-use would be possible for IBP oxidation as well. The relatively low cost, stability and reusability of $\mathrm{Fe}_{3} \mathrm{O}_{4}$ make it an environmentally friendly catalyst to remediate an increasing number of environmental pollutants.

\section{Acknowledgments}

The authors would like to acknowledge the Natural Sciences and Engineering Research Council of Canada (NSERC) and Eugenie Ulmer Lamothe Chemical Engineering Fund (McGill University) for the financial support provided in this work. The authors would also like to thank Hongxia Li at the Water Quality Centre at Trent University for her help in identifying the degradation products.

\section{References}

Adams TB, Cohen SM, Doull J, Feron VJ, Goodman JI, Marnett LJ, et al. The FEMA GRAS assessment of benzyl derivatives used as flavor ingredients. Food Chem Toxicol 2005;43:1207-40.

Ahmad M, Teel AL, Watts RJ. Persulfate activation by subsurface minerals. J Contam Hydrol 2010;115:34-45.

Buser H-R, Poiger T, MÃller MD. Occurrence and environmental behavior of the chiral pharmaceutical drug ibuprofen in surface waters and in wastewater. Environ Sci Technol 1999;33:2529-35.

Caviglioli G, Valeria P, Brunella P, Sergio C, Attilia A, Gaetano B. Identification of degradation products of ibuprofen arising from oxidative and thermal treatments. J Pharm Biomed Anal 2002;30:499-509.

Evanko CR, Dzombak DA. Surface complexation modeling of organic acid sorption to goethite. J Colloid Interface Sci 1999;214:189-206.

Fent K, Weston AA, Caminada D. Ecotoxicology of human pharmaceuticals. Aquat Toxicol 2006;76:122-59.

Gagnon C, Lajeunesse A. Persistence and fate of highly soluble pharmaceutical products in various types of municipal waste water treatment plants. Waste Manag Environ IV 2008;109:799-807.

Goi A, Veressinina Y, Trapido M. Degradation of salicylic acid by Fenton and modified Fenton treatment. Chem Eng J 2008;143:1-9.

Heberer T. Occurrence, fate, and removal of pharmaceutical residues in the aquatic environment: a review of recent research data. Toxicol Lett 2002;131:5-17.

Hofmann J, Freier U, Wecks M, Hohmann S. Degradation of diclofenac in water by heterogeneous catalytic oxidation with $\mathrm{H}_{2} \mathrm{O}_{2}$. Appl Catal Environ 2007;70: 447-51.

Huber MM, Canonica S, Park G-Y, von Gunten U. Oxidation of pharmaceuticals during ozonation and advanced oxidation processes. Environ Sci Technol 2003;37: $1016-24$.

Huber MM, Korhonen S, Ternes TA, von Gunten U. Oxidation of pharmaceuticals during water treatment with chlorine dioxide. Water Res 2005;39:3607-17.

Kostka JE, Nealson KH. Chapter 3: isolation, cultivation, and characterization of iron- and manganese-reducing bacteria. New York: Oxford University Press; 1998.

Lee Y, von Gunten U. Oxidative transformation of micropollutants during municipal wastewater treatment: comparison of kinetic aspects of selective (chlorine, chlorine dioxide, ferrateVI, and ozone) and non-selective oxidants (hydroxyl radical). Water Res 2009;44:555-66.

Liang C, Bruell CJ, Marley MC, Sperry KL. Persulfate oxidation for in situ remediation of TCE. I. Activated by ferrous ion with and without a persulfate-thiosulfate redox couple. Chemosphere 2004a;55:1213-23.

Liang C, Bruell CJ, Marley MC, Sperry KL. Persulfate oxidation for in situ remediation of TCE. II. Activated by chelated ferrous ion. Chemosphere 2004b;55: 1225-33.

Liang C, Huang C-F, Chen Y-J. Potential for activated persulfate degradation of BTEX contamination. Water Res 2008;42:4091-100.

Lovley DR, Phillips EJP. Organic matter mineralization with reduction of ferric iron in anaerobic sediments. Appl Environ Microbiol 1986;51:6.

Madhavan J, Grieser F, Ashokkumar M. Combined advanced oxidation processes for the synergestic degradation of ibuprofen in aqueous environments. J Haz Mat 2010;178(1-3):202-8

Matta R, Hanna K, Chiron S. Fenton-like oxidation of 2,4,6-trinitrotoluene using different iron minerals. Sci Total Environ 2007;385:242-51.

Matta R, Hanna K, Chiron S. Oxidation of phenol by green rust and hydrogen peroxide at neutral pH. Sep Purif Technol 2008a;61:442-6.

Matta R, Hanna K, Kone T, Chiron S. Oxidation of 2,4,6-trinitrotoluene in the presence of different iron-bearing minerals at neutral $\mathrm{pH}$. Chem Eng J 2008b; $144: 453-8$

Méndez-Arriaga F, Torres-Palma RA, Pétrier C, Esplugas S, Gimenez J, Pulgarin C. Ultrasonic treatment of water contaminated with ibuprofen. Water Res 2008;42: 4243-8.

Méndez-Arriaga F, Esplugas S, Giménez J. Degradation of the emerging contaminant ibuprofen in water by photo-Fenton. Water Res 2010;44:589-95.

Miranda MA, Morera I, Vargas F, Gómez-Lechón MJ, Castell JV. In vitro assessment of the phototoxicity of anti-inflammatory 2-arylpropionic acids. Toxicol Vitro 1991;5: 451-5.

Monahan MJ, Teel AL, Watts RJ. Displacement of five metals sorbed on kaolinite during treatment with modified Fenton's reagent. Water Res 2005;39:2955-63.

Peyton GR. The free-radical chemistry of persulfate-based total organic carbon analyzers. Mar Chem 1993;41:91-103.

Pomati F, Netting AG, Calamari D, Neilan BA. Effects of erythromycin, tetracycline and ibuprofen on the growth of Synechocystis sp. and Lemna minor. Aquat Toxicol 2004;67:387-96.

Poyatos JM, Muñio MM, Almecija MC, Torres JC, Hontoria E, Osorio F. Advanced oxidation processes for wastewater treatment: state of the art. Water Air Soil Pollut 2009.

Schwertmann U, Cornell RM. Magnetite. Iron oxides in the laboratory: preparation and characterization. Weinheim: WILEY-VCH Verlag GmbH; 2000.

Skoumal M, Rodríguez RM, Cabot PL, Centellas F, Garrido JA, Arias C, et al. Electro-Fenton, UVA photoelectro-Fenton and solar photoelectro-Fenton degradation of the drug ibuprofen in acid aqueous medium using platinum and boron-doped diamond anodes. Electrochim Acta 2009;54:2077-85.

Weiss J. The free radical mechanism in the reactions of hydrogen peroxide. In: Frankenburg VIK WG, Rideal EK, editors. Advances in catalysis, Volume 4. Academic Press; 1952. p. 343-65. 
Xue X, Hanna K, Abdelmoula M, Deng N. Adsorption and oxidation of PCP on the surface of magnetite: kinetic experiments and spectroscopic investigations. Appl Catal Environ 2009a;89:432-40.

Xue X, Hanna K, Deng N. Fenton-like oxidation of Rhodamine B in the presence of two types of iron(II, III) oxide. J Hazard Mater 2009b;166:407-14.

Xue X, Hanna K, Despas C, Wu F, Deng N. Effect of chelating agent on the oxidation rate of PCP in the magnetite $/ \mathrm{H}_{2} \mathrm{O}_{2}$ system at neutral pH. J Mol Catal A Chem 2009c;311: 29-35.
Yan J, Lei M, Zhu L, Anjum MN, Zou J, Tang H. Degradation of sulfamonomethoxine with $\mathrm{Fe}_{3} \mathrm{O}_{4}$ magnetic nanoparticles as heterogeneous activator of persulfate. J Hazard Mater 2010;186:1398-404.

Zorita S, Mårtensson L, Mathiasson L. Occurrence and removal of pharmaceuticals in a municipal sewage treatment system in the south of Sweden. Sci Total Environ 2009;407:2760-70. 